\title{
Guest Editor: Thomas R. Ten Have, Ph.D., M.P.H. (1958-2011)
}

\author{
Scarlett Bellamy • Daniel F. Heitjan • \\ Edmund Weisberg • Xihong Lin
}

Received: 19 June 2011 / Accepted: 22 June 2011 / Published online: 9 July 2011

(C) International Chinese Statistical Association 2011

Thomas R. Ten Have, Professor of Biostatistics in the Department of Biostatistics and Epidemiology of the University of Pennsylvania, passed away on May 1, 2011 after a lengthy battle with myeloma. He was 53. Tom served as the Guest Editor for this Special Issue on Statistical Methods for Comparative Effectiveness Research.

The eldest son of missionaries, Tom Ten Have was born in Sioux City, Iowa and spent his childhood in Korea, Malaysia, and Nepal. When he was 12 his family returned to the United States, settling in Grand Rapids, Michigan. In high school Tom pursued an interest in art, and at Grand Rapids Junior College he studied accounting and mathematics. In 1978 he enrolled in the undergraduate business program at the University of Michigan in Ann Arbor, where he soon discovered a liking for data management and analysis. Changing his major to statistics, he took a job as a research assistant in the Department of Biostatistics in 1980 and earned a B.A. in Statistics in 1981 and an M.P.H. in Biostatistics in 1982.

Tom worked for several years as a master's-level statistician analyzing craniofacial and orthodontic data. He returned to the Department of Biostatistics as a doctoral student in 1989 and earned his Ph.D. under Mark Becker in 1991, studying aspects of contingency table analysis. His first faculty appointment was as Assistant Professor of Biostatistics under Dick Landis in the Center for Biostatistics and Epidemiology at the Penn State College of Medicine in Hershey. Later he joined Dick in moving to the newly founded Department of Biostatistics and Epidemiology at the University of Pennsylvania, where he was appointed Associate Professor (1997) and Tenured Pro-

S. Bellamy · D.F. Heitjan · E. Weisberg

University of Pennsylvania, Philadelphia, USA

X. Lin (凶)

Harvard University, Cambridge, USA

e-mail: xlin@hsph.harvard.edu 
fessor of Biostatistics (2001). From 2005 he was director of the Biostatistics Analysis Center, and from 2006 associate director of the Biostatistics Unit.

Tom made many excellent contributions to statistical methods research; his papers on loglinear models, longitudinal analysis of categorical data with missing observations, causal inference in clinical trials with non-compliance, and dynamic treatment regimes are particularly well known. Tom was also a leader in the application of statistics in psychiatry. Among his enduring contributions was co-founding the Columbia-Penn-Yale Annual Symposium on Statistics in Psychiatry, now in its 13th year. His work in this area was recognized with the 2007 Harvard Award in Psychiatric Epidemiology and Biostatistics.

Tom earned many other professional honors in his brief career: He was Phi Beta Kappa in college, a Regent's Fellow in graduate school, Fellow of the ASA (1999), elected Chair of the ASA Biometrics Section (2007), and recipient of the Samuel Martin Health Evaluation Sciences Research Award from the University of Pennsylvania School of Medicine (2008).

Tom served on numerous grant review panels, data monitoring boards, Institute of Medicine committees, and the like, and had been an Associate Editor for Applied Statistics, Biometrics, and Statistics in Medicine. He was a devoted teacher and research mentor, having advised or co-advised nine Ph.D.'s.

Tom impressed all who knew him with his great virtue and integrity. He was a sincere, loyal, dedicated, humble, trustworthy, and generous man. Although he worked hard to advance his own career, he seemed to spend just as much time advising and encouraging junior colleagues at Penn and elsewhere-not just talking to them but applying his knowledge and influence to help them identify funding, collaborators, speaking engagements and other professional opportunities. Tom was committed to opening the doors of opportunity to all, including individuals from groups that in the past have been poorly represented in scientific professions. He was active in both recruiting minority students into statistics and in mentoring young minority statisticians.

Tom contributed with energy and distinction to every aspect of biostatistical endeavor-he did first-class applied work, created novel statistical methods, held grants of his own, helped others write grants, directed master's-level statisticians, supported and advised students, and performed a vast amount of administration and mentoring at all levels. But despite the heavy burdens he shouldered, he was unfailingly polite, patient, kind, thoughtful and gentle, putting the needs of others first even during his long and wearying struggle with cancer. His loss is keenly felt by friends and colleagues near and far. 